\title{
Survival and morbidity of very low birth weight infants in a South American Neonatal Network
}

\author{
Rocío Fernández, M.D., ${ }^{a}$ Ivonne D'Apremont, M.D., ${ }^{b}$ Angélica Domínguez, M.S., \\ José L. Tapia, M.D., ${ }^{\text {and Neocosur Neonatal Network }}{ }^{e}$
}

\begin{abstract}
Objective. To analyze survival and relevant morbidity by gestational age (GA) in very low birth weight (VLBW) infants ( $<1500 \mathrm{~g}$ ) and, based on these data, develop a fact sheet to provide information to perinatal healthcare providers and very low birth weight preterm infants'parents. Study Design. Data were prospectively collected in relation to newborn infants with a birth weight between $500 \mathrm{~g}$ and $1500 \mathrm{~g}$ admitted to 45 sites of the Neocosur Neonatal Network (Red Neonatal Neocosur) between January 2001 and December 2011.

Results. Data on 8234 VLBW with a GA between $24^{+0}$ and $31^{+6}$ weeks were analyzed. Overall mortality was 26\% (95\% CI: $25.0-26.9$ ), including $2.6 \%$ of deaths in the delivery room. Fact sheets for survival and morbidity for each week of gestation were developed based on collected data. Survival at discharge increased from $29 \%$ at 24 weeks of GA to $91 \%$ at 31 weeks of GA $(p<0.001)$. The incidence of relevant neonatal morbidity was inversely related to GA $(p<0.001)$. Overall, $30.8 \%$ had retinopathy of prematurity, $25 \%$ bronchopulmonary dysplasia, $10.9 \%$ necrotizing enterocolitis, $7.2 \%$ severe intraventricular hemorrhage, and $4.6 \%$ periventricular leukomalacia. Among survivors, $47.3 \%$ had none of these five conditions.

Conclusions. A tool for use in a clinical setting was developed based on updated regional data for establishing week-to-week survival and morbidity of newborn infants born between $24^{+0}$ and $31^{+6}$ weeks of GA. This information could be used to make decisions related to perinatal care and for counseling parents.

Key words: very low birth weight infant, gestational age, survival, morbidity.
\end{abstract}

http:/ /dx.doi.org/10.5546/aap.2014.eng.405

\section{INTRODUCTION}

Prematurity has been a growing health problem around the world, with a global incidence of $11.1 \%$ and significant geographic differences, ranging from $5 \%$ in developed countries to $18 \%$ in low-income countries. ${ }^{1}$

Prematurity is the main cause of perinatal morbidity and mortality and the second leading cause of death in children younger than
5 years old, and results in a million deaths every year. ${ }^{2,3}$

Although very low birth weight (VLBW) infants, those born with a weight less than $1500 \mathrm{~g}$, account for $1 \%-1.5 \%$ of all births, they significantly contribute to neonatal (50\%-70\%) and infant $(25 \%-40 \%)$ mortality in the South American region.-6

Survival in this group has increased worldwide, especially in the past 20 years, ${ }^{7-9}$ with marked intraand inter-countries differences. ${ }^{6,10}$ However, such survival has been accompanied by a high percentage of potentially serious long-term sequelae. In addition to the younger gestational age (GA) and lower birth weight (BW), ${ }^{11,12}$ the presence of intraventricular hemorrhage (IVH), periventricular leukomalacia (PVL), bronchopulmonary dysplasia (BPD), retinopathy of prematurity (ROP), and necrotizing enterocolitis (NEC) ${ }^{13-}$ ${ }^{18}$ has been associated with a worse prognosis.

Clinical management of very low birth weight preterm infants may depend on the perception that healthcare providers have regarding their expectancy of survival, which is usually underestimated by doctors, as shown by different studies. ${ }^{19,20}$ Actual estimations of the prognosis of VLBW survival and morbidity are essential, and such information will help to make perinatal care decisions and provide information to parents. It has been shown that visual methods work better for communicating complex information..$^{21}$

Our objective is to analyze the variation observed in terms of survival and most relevant pathologies in relation to the long-term prognosis of VLBW based on their GA and using 
regional and updated data from a regional neonatal network. Such results would allow us to prepare an easy and practical visual tool to provide information to perinatal healthcare providers and VLBW parents.

\section{POPULATION AND METHODS}

Design. Retrospective cohort study

Population. Our study was based on the Neocosur Neonatal Network (Red Neonatal Neocosur) database, which currently includes 26 neonatal intensive care units (NICUs) from six South American countries: Argentina, Brazil, Chile, Paraguay, Peru and Uruguay.

All member sites are affiliated teaching tertiary care facilities. The network offers an ongoing database that prospectively collects data on VLBW (BW between $500 \mathrm{~g}$ and $1500 \mathrm{~g}$ ) born at member sites. Data are collected for all newborn infants until discharge or death. Those transferred to or from other sites and stillbirths are excluded. Site and patient identity is kept confidential.

For data validation, cases included in the network are periodically reviewed by two trained nurses, who contact sites in case of missing or inconsistent information. The database is reviewed annually by a statistician and a neonatologist from the Database Unit. Analyzed data are presented in an annual report with the network's updated results.

In this study, included data referred to live newborn infants (NBIs) with a BW between $500 \mathrm{~g}$ and $1500 \mathrm{~g}$ and a GA between $24^{+0}$ and $31^{+6}$ weeks hospitalized between January 2001 and December 2011 in any of the 15 sites that have participated in the Neocosur Network for ten or more years. The $24^{+0}$ week lower limit was selected because it is considered controversial to perform resuscitation techniques at a younger GA and because many younger NBIs weigh less than $500 \mathrm{~g}$. NBIs with life-threatening major malformations were excluded.

Demographic data and clinical results were prospectively and systematically recorded at the Neocosur Network sites using an online electronic form available in their web site (www.neocosur.org).

\section{Definitions}

Diagnostic criteria for included pathologies were predefined by the Neocosur Network. Mortality was defined as death before hospital discharge, including death in the delivery room.

GA was determined using the best obstetric estimate based on the last menstrual cycle, obstetric factors and prenatal ultrasounds during the first, second or third trimesters, if available. BPD was defined as oxygen requirement at 36 weeks of corrected GA. ${ }^{22}$ IVH was diagnosed with cranial ultrasonography or autopsy, and was classified according to Papile and Bursten, ${ }^{23}$ who categorize grade III and IV IVH as severe. PVL was diagnosed by the presence of an intraparenchymal necrotic lesion in the white matter identified in cranial ultrasonography. NEC was defined according to Bell's criteria ${ }^{24}$ and confirmed using an abdomen X-ray (pneumatosis and/or perforation), surgical findings or an autopsy. ROP was diagnosed with a test administered by an ophthalmologist as of 28 days of life and categorized as grade 1 to 5 as per the international classification. ${ }^{25}$

\section{Ethical Considerations}

The study was approved by the Ethics Committee of Pontificia Universidad Católica de Chile.

\section{Statistical Analysis}

Survival at discharge was estimated for all patients according to their GA. The incidence of neonatal relevant morbidities was estimated based on survivors. Included morbidities were ROP, BPD, NEC, PVL and severe IVH. The percentage of survivors with no morbidity was also estimated, i.e., those who did not have any of these five pathologies.

Outcome measures included in the analysis were GA, BW, sex, antenatal corticosteroid therapy, antenatal care, maternal age, multiple pregnancy, and mode of delivery. Continuous outcome measures are described as average \pm standard deviation (SD), while categorical outcome measures are described as number of cases and percentage. To assess differences between deceased and living NBIs, Student's $t$ tests were performed for independent samples in the case of continuous outcome measures, while Pearson's chi-square tests were used in the case of categorical outcome measures.

In addition, survival and comorbidities incidences were described for each GA week using percentages and $95 \%$ confidence intervals (CI). Linear trends in these incidences were assessed by estimating $p$ values with CochraneArmitage's test. Spearman's correlation test was used to assess the linear association between GA and BW.

All $p$ values were estimated using two-tailed 
tests, and those lower than 0.05 were considered significant.

Data were analyzed using the SPSS 17.0 statistical software.

\section{RESULTS}

\section{General Data}

A total of 13181 VLBW were born in the 26 sites member of the Neocosur Neonatal Network between January $1^{\text {st }}, 2001$ and December $31^{\text {st }}, 2011$. Of them, 8234 who met the inclusion criteria were analyzed (Figure 1).

Table 1 summarizes demographic characteristics for the overall analyzed population, both survivors and deceased. There were no survival data for 48 cases $(0.6 \%$ loss $)$.

\section{Survival at Discharge}

Of the 8234 analyzed NBIs, $18.5 \%$ were born at 30 weeks of GA, while $6.6 \%$ were born at 24 weeks of GA. Of them, $74 \%(\mathrm{n}=6060)$ survived until discharge, $2.6 \%$ died in the delivery room, and $23.4 \%$ died while hospitalized. Specific survival by GA for all NBIs progressively increased with a greater GA $(p<0.001)$ and ranged between $28.6 \%$ in NBIs born at 24 weeks and $90.6 \%$ in those born at 31 weeks (Figure 2). The highest increase in survival occurred between 24 and 25 weeks of GA, with an $18.1 \%$ increase. Such increase was less evident between 29 and 31 weeks (from 2.3\% to 2.8\%). Table 2 shows the demographic characteristics, the incidence of mortality and morbidity-free survival per week of GA.

\section{Neonatal Mortality}

Figure 3 shows the incidence, overall and by
GA, of most relevant pathologies in relation to long-term prognosis. The most frequent conditions were ROP $(30.8 \%)$ and BPD $(25 \%)$, while PVL was the less frequent one $(4.6 \%)$. Among survivors, $47.3 \%$ had none of these five conditions. The incidence of ROP, BPD, NEC, severe IVH and PLV was inversely related to GA $(p<0.001)$; see Figure 3.

\section{Visual Aids}

Based on analysis data and a template previously used by Guillén U., et al., ${ }^{21}$ a fact sheet was developed to show survival for each GA week (Figure 2). A second fact sheet was developed

FIGURE 1. Patient flowchart, Neocosur Network, 2001-2011

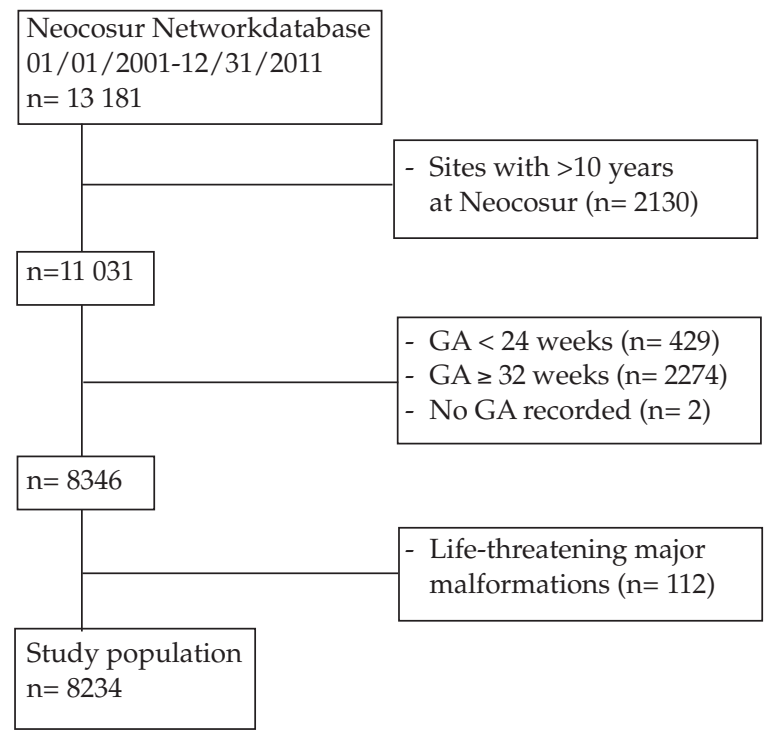

TABLE 1. Characteristics of the study population, Neocosur Network, 2001-2011

\begin{tabular}{lcccc}
\hline \multicolumn{5}{c}{ Live newborn infants born with 500 g-1500 g } \\
Demographic characteristics & Total (n= 8186) & Survivors (n= 6060) & Deceased (n= 2126) & $p$ value \\
\hline Gestational age (weeks) & $28.1 \pm 2.1$ & $28.6 \pm 1.9$ & $26.8 \pm 2.1$ & $<0.001$ \\
Birth weight (g) & $1047 \pm 262$ & $1109 \pm 240$ & $869 \pm 239$ & $<0.001$ \\
Maternal age (years) & $27.4 \pm 7.4$ & $27.7 \pm 7.4$ & $26.7 \pm 7.3$ & $<0.001$ \\
Male gender (\%) & 52.2 & 50.8 & 55.9 & $<0.001$ \\
Antenatal corticosteroids (\%)+ & 78.4 & 83.4 & 63.9 & $<0.001$ \\
Antenatal care (\%) & 87.1 & 89.7 & 79.6 & $<0.001$ \\
Multiple pregnancy (\%) & 18.5 & 19.3 & 16.2 & 0.002 \\
C-section (\%)\# & 68.3 & 71.7 & 58.6 & $<0.001$ \\
\hline
\end{tabular}

Continuous outcome measures are expressed as average \pm SD.

*Lack of data for 48 cases $(0.6 \%$ loss).

t At least one dose.

\# C-section with and without labor. 
to show the incidence of these five pathologies included in the analysis by week of GA (Table 3). All values included in the fact sheets were rounded up to the nearest conservative multiple of 5. The survival and incidence of pathologies are expressed as percentage with its respective 95\% confidence interval between brackets.

These fact sheets are available online as

FIGURE 2. Fact sheets illustrating survival at discharge by gestational age for very low birth weight infants born at sites members of the Neocosur Neonatal Network between January 2001 and December 2011. Average survival (\%) for each week of gestational age and the corresponding $95 \%$ confidence interval are shown.
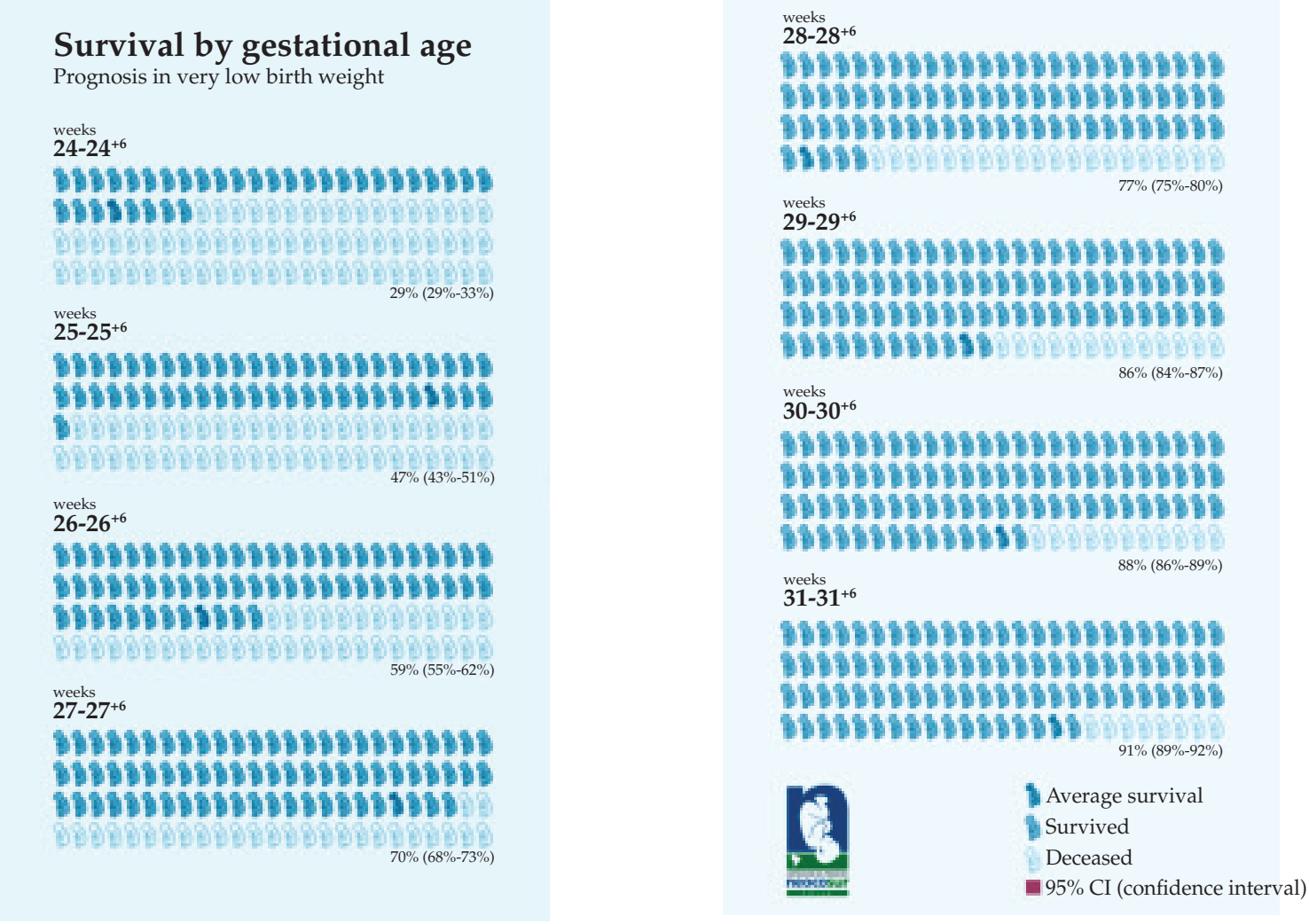

TABle 2. Demographic characteristics, mortality and morbidity-free neonatal survival in the study population by week of gestational age, Neocosur Network, 2001-2011

\begin{tabular}{lcccccc}
\hline GA (weeks) & n (\%) & PN (g) & $\begin{array}{c}\text { Male } \\
\text { gender (\%) }\end{array}$ & $\begin{array}{c}\text { Antenatal } \\
\text { corticosteroids (\%) }\end{array}$ & $\begin{array}{c}\text { Mortality (\%) } \\
\text { Morbidity-free } \\
\text { survival }^{*} \text { (\%) }\end{array}$ \\
\hline 24 & $540(6.6)$ & $698 \pm 131$ & 57.5 & 63.6 & 71.4 & 6.4 \\
25 & $643(7.8)$ & $761 \pm 134$ & 52.0 & 76.9 & 53.3 & 10.3 \\
26 & $806(9.8)$ & $849 \pm 169$ & 54.8 & 75.9 & 41.1 & 20.1 \\
27 & $1026(12.5)$ & $951 \pm 187$ & 52.5 & 79.3 & 29.6 & 30.3 \\
28 & $1334(16.2)$ & $1049 \pm 214$ & 53.9 & 79.1 & 22.7 & 45.8 \\
29 & $1319(16.0)$ & $1151 \pm 216$ & 51.9 & 80.3 & 14.5 & 53.5 \\
30 & $1522(18.5)$ & $1217 \pm 203$ & 49.9 & 79.7 & 12.2 & 62.3 \\
31 & $1044(12.7)$ & $1257 \pm 192$ & 48.5 & 81.4 & 9.4 & 68.4 \\
Total & $8234(100)$ & $1046 \pm 262$ & 52.2 & 78.2 & 26.0 & 47.3 \\
$p$ value & & $<0.001+$ & & $<0.001^{\#}$ & $<0.01^{\#}$ & $0.001^{\#}$ \\
\hline
\end{tabular}

GA: gestational age; BW: birth weight, expressed as average \pm SD.

* Survival with no ROP, BPD, severe IVH, PVL, NEC.

$+p$ value estimated as per Spearman's correlation test.

\# $\mathrm{p}$ value estimated as per Cochrane-Armitage's trend test. 
supplementary material together with this printable publication.

\section{DISCUSSION}

This was an innovative study because of three reasons: a) it describes the survival and incidence of relevant morbidity for VLBW born between $24^{+0}$ and $31^{+6}$ weeks of GA using regional data; $b$ ) results are analyzed based on week of GA; c) a visual tool was developed to be used as an aid in the clinical setting.

According to WHO data, ${ }^{2}$ more than $90 \%$ of extremely premature infants born in lowincome countries die in their first days of life due to inadequate neonatal care; however, less than $10 \%$ of infants born at this GA die in highincome countries. It is therefore essential to collect regional data regarding the morbidity and mortality of these infants. At present, the overall mortality of VLBW according to the Neocosur Network is 26\% (95\% CI: 25.0-26.9).

To our knowledge, this is the first updated report in the literature based on a South American patient database. The Neocosur Network published a previous report ${ }^{6}$ in 2002, which included only 11 sites and 385 cases.

Mortality in infants with a birth weight less than $1500 \mathrm{~g}$ reported by neonatal networks from developed countries (EuroNeoNet, Vermont Oxford, Canadian Neonatal Network, NICHD) ranges between $12.4 \%$ and $28 \%{ }^{26-29}$

However, caution should be exercised when analyzing these differences because mortality rates vary significantly depending on the denominator used ${ }^{30}$ and because many studies do not even specify the denominator used. In our study, mortality was estimated based on all living NBIs, including those who die in the delivery room; this is similar to the mortality rate reported by the EuroNeoNet ${ }^{26}(12.4 \%)$. As opposed to this, the Canadian Neonatal Network ${ }^{29}$ reports a mortality rate of $14.7 \%$ using as denominator only NBIs admitted to the NICU. It should also

FIGURE 3. Survival and morbidity incidence by weeks of gestational age

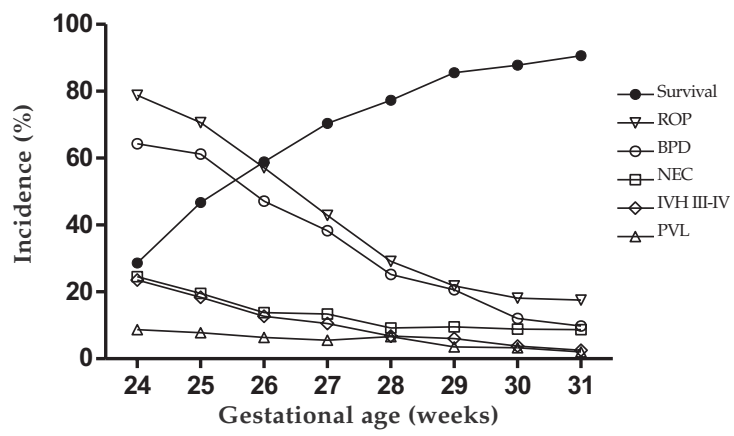

ROP: retinopathy of prematurity; BPD: bronchopulmonary dysplasia; PVL: periventricular leukomalacia;

NEC: necrotizing enterocolitis;

IVH, grade III-IV: severe intraventricular hemorrhage.

TABLE 3. Fact sheet to show the incidence of overall morbidity and by week of gestational age for very low birth weight infants born at sites member of the Neocosur Neonatal Network between January 2001 and December 2011

\begin{tabular}{lccccc}
\hline Weeks & $\begin{array}{c}\text { Bronchopulmonary } \\
\text { dysplasia }\end{array}$ & $\begin{array}{c}\text { Necrotizing } \\
\text { enterocolitis }\end{array}$ & $\begin{array}{c}\text { Periventricular } \\
\text { leukomalacia }\end{array}$ & $\begin{array}{c}\text { Retinopathy } \\
\text { of prematurity }\end{array}$ & $\begin{array}{c}\text { Intraventricular } \\
\text { hemorrhage } \\
\text { grade III and IV }\end{array}$ \\
\hline $24-24^{+6}$ & Incidence 95\% CI & Incidence 95\% CI & Incidence 95\% CI & Incidence 95\% CI & Incidence 95\% CI \\
$25-25^{+6}$ & $61 \%(57-72)$ & $25 \%(18-31)$ & $9 \%(4-13)$ & $79 \%(72-86)$ & $24 \%(17-30)$ \\
$26-26^{+6}$ & $47 \%(43-52)$ & $20 \%(15-24)$ & $8 \%(5-11)$ & $71 \%(65-76)$ & $18 \%(14-23)$ \\
$27-27^{+6}$ & $38 \%(35-42)$ & $14 \%(11-17)$ & $6 \%(4-9)$ & $57 \%(53-62)$ & $13 \%(10-16)$ \\
$28-28^{+6}$ & $25 \%(22-28)$ & $13 \%(11-16)$ & $6 \%(4-7)$ & $43 \%(39-47)$ & $11 \%(8-13)$ \\
$29-29^{+6}$ & $21 \%(18-23)$ & $10 \%(8-11)$ & $7 \%(5-8)$ & $29 \%(26-32)$ & $7 \%(5-8)$ \\
$30-30^{+6}$ & $12 \%(10-14)$ & $9 \%(7-10)$ & $3 \%(2-4)$ & $22 \%(19-24)$ & $6 \%(5-7)$ \\
$31-31^{+6}$ & $10 \%(8-12)$ & $9 \%(7-11)$ & $2 \%(1-3)$ & $18 \%(16-20)$ & $4 \%(3-5)$ \\
Total & $25 \%(24-26)$ & $11 \%(10-12)$ & $5 \%(4-5)$ & $18 \%(15-20)$ & $3 \%(1-4)$ \\
\hline
\end{tabular}


be considered that inclusion criteria vary among the different studies. For example, the NICHD ${ }^{28}$ includes infants born between 22 and 28 weeks of GA with a BW between $401 \mathrm{~g}$ and $1500 \mathrm{~g}$, while our study included NBIs with a BW between $500 \mathrm{~g}$ and $1500 \mathrm{~g}$ but with a GA between $24^{+0}$ and $31^{+6}$ weeks.

Prematurity leads to multiple complications, and many survivors face life-long disability. ${ }^{31}$ Mortality is inversely related to GA; however, there is no GA which is totally free of morbidity. The five pathologies analyzed in this study were selected due to their relevance in long-term prognosis and their association to an increased risk of neurological disability, from visual and hearing impairment to cerebral palsy. ${ }^{13-18}$ Our findings that only $47.3 \%$ (Figure 3 ) of survivors are morbidity-free are consistent with other reports. ${ }^{28}$

GA and BW are major determining factors for survival and morbidity, and there is a combined effect resulting from both variables. ${ }^{3,11,12}$ However, GA has a greater influence on the prognosis of VLBW. ${ }^{31}$ In addition, given that BW is unknown before delivery, it is important to provide information on the prognosis based on GA. Week-to-week survival by GA is very useful in perinatal care settings to decide on the chances of delivery in situations where there is risk for both the mother and the baby. In ourstudy, survival by GA for all NBIs increases progressively with a greater GA $(p<0.001)$ and ranges between $28.6 \%$ at 24 weeks of GA and $90.6 \%$ at 31 weeks of GA (Figure 1), with an overall survival of $74 \%$ (95\% CI: 73.1-75.0). The most remarkable increase is observed between 24 and 25 weeks, with $18.1 \%$ and estimated at $1.4 \%$ for each day in the womb between $24^{+0}$ weeks and 30-31 weeks. The studies by Bolisetty, et al. ${ }^{32}$ (Australia) and Stoll, et al. ${ }^{28}$ (USA) analyzed similar survival and morbidity variables on 2315 and 9575 patients, respectively, and found that survival was greater than that reported by our study for each week of GA, and also a lower incidence for each of the pathologies analyzed, which may be accounted for by difference in the population, perinatal practice and resource availability.

Perinatal clinical management of VLBW may depend on the knowledge regarding their expectancy of survival and the risk of long-term sequelae. ${ }^{32}$ Our results could be used to improve the quality of care provided to preterm NBIs since it has been demonstrated that individual clinical judgment tends to underestimate survival probabilities in very low birth weight preterm infants, especially those born at the threshold of viability. ${ }^{19,20}$

Doctors and parents recognize that they require information on the prognosis of very low birth weight preterm infants (survival and long-term sequelae). ${ }^{21}$ The American Academy of Pediatrics and the American College of Obstetrics and Gynecology have indicated that it is essential to inform future parents facing an extremely preterm delivery of the prognosis regarding survival and sequelae, and that this information should be clear and consistent, based on updated, local data. ${ }^{33-34}$ Most published results tend to be tedious and hard to understand for parents. Guillén, et al. ${ }^{21}$ and Paul, et al. ${ }^{35}$ found that between $63 \%$ and $72 \%$ of parents prefer to have quantitative data to qualitative assessments, and $60 \%$ of them wish to have information on survival, while they also express interest on sequelae. Fifty-seven percent of interviewed parents would rather have visual information, which increased understanding from 39\% to $71 \%$ in parents who had no previous experience. ${ }^{21}$ Seventy-seven percent of doctors believe that visual aids (brochures, images, videos) may help themcounsel and provide information to parents during prenatal care.

Our study has the following strengths: it provides updated information on the prognosis of VLBW born in South America, based on a large cohort which includes public and private sites, and is therefore more relevant than individual unit studies. We developed a simple and practical tool to estimate the survival and morbidity incidence for each week of GA. Notwithstanding, our study has certain limitations: it is a compilation of a multi-center database, where there is missing data. The determination of GA using the best obstetric estimate may be inaccurate in some cases; however, given that this is a very large sample, it should not impact results. We did not include GA determined by the neonatal examination because of the regional differences observed in the neonatal practice. In addition, since we did not include NBIs with a BW less than $500 \mathrm{~g}$, some patients that were born at the GA analyzed in this study were excluded. To sum up, we developed a fact sheet that helps to establish week-to-week survival and morbidity of infants born between $24^{+0}$ and $31^{+6}$ weeks of GA. With this information we were able to provide an educational tool that can be used to make perinatal care decisions and that could be delivered to parents of very low birth 
weight preterm infants. We believe that this type of instrument should be periodically updated for each population and based on most recent data, and it would also be very useful to prepare a sitespecific fact sheetaccording to each site's reality.

\section{Acknowledgments}

We would like to thank all sites members of the Neocosur Network for their participation in this study.

\section{REFERENCES}

1. Blencowe H, Cousens S, Oestergaard MZ, Chou D, et al. National, regional, and worldwide estimates of preterm birth rates in the year 2010 with time trends since 1990 for selected countries: a systematic analysis and implications. Lancet 2012;379(9832):2162-72.

2. March of Dimes, PMNCH, Save the Children, WHO. Born too soon: the global action report on preterm birth. Geneva: World Health Organization; 2012. Available at: http:// www.who.int/pmnch/media/ news/2012/201204_borntoosoon-report.pdf. [Accessed on: June 5, 2014].

3. Lawn JE, Cousens S, Zupan J, Lancet Neonatal Survival Steering Team. 4 million neonatal deaths: when? Where? Why? Lancet 2005;365(9462):891-900.

4. Secretaría de Políticas, Regulación e Institutos. Dirección de Estadísticas e Información en Salud. Estadísticas Vitales. Información Básica 2012. Buenos Aires: Argentina, Ministerio de Salud. Available at: http:/ /www.deis.gov. ar/Publicaciones/Archivos/Serie5Nro56.pdf. [Accessed on: February 2,2014].

5. Chile, Ministerio de Salud. Departamento de Estadísticas e Información de Salud. Estadísticas Vitales. Informe anual 2009. Santiago de Chile; 2011. Available at: http:/ /www. ine.cl/canales/chile_estadistico/demografia_y_vitales/ estadisticas_vitales/2011/Vitales_2009_21102011.pdf. [Accessed on: June 9, 2014].

6. Grupo Colaborativo Neocosur. Very-low-birth-weight infant outcomes in 11 South American NICUs. J Perinatol 2002;22(1):2-7.

7. Gonzalez R, Merialdi M, Lincetto O, Lauer J, et al. Reduction in neonatal mortality in Chile between 1990 and 2000. Pediatrics 2006;117(5):e949-54.

8. Fanaroff AA, Stoll BJ, Wright LL, Carlo WA, et al. Trends in neonatal morbidity and mortality for very low birthweight infants. Am J Obstet Gynecol 2007;196(2):147.e1-8.

9. Alexander GR, Kogan M, Bader D, Carlo W, et al. US birth weight/gestational age-specific neonatal mortality: 19951997 rates for whites, hispanics and blacks. Pediatrics 2003;111(1):e61-6.

10. Beck S, Wojdyla D, Say L, Betran AP, et al. The worldwide incidence of preterm birth: a systematic review of maternal mortality and morbidity. Bull World Health Organ 2010;88(1):31-8.

11. Mardones F, Marshall G, Viviani P, Villarroel L, et al. Estimation of individual neonatal survival using birthweight and gestational age: a way to improve neonatal care. J Health Popul Nutr 2008;26(1):54-63.

12. Draper ES, Manktelow B, Field DJ, James D. Prediction of survival for preterm births by weight and gestational age: restrospective population based study. BMJ 1999;319(7217):1093-7.

13. Schmidt B, Asztalos EV, Roberts RS, Robertson CM, et al. Impact of bronchopulmonary dysplasia, brain injury, and severe retinopathy on the outcome of extremely low-birth-weight infants at 18 months: results from the trial of indomethacin prophylaxis in preterms. JAMA 2003;289(9):1124-9.

14. Hintz SR, Kendrick DE, Stoll BJ, Vohr BR et al. Neurodevelopmental and growth outcomes of extremely low birth weight infants after necrotizing enterocolitis. Pediatrics 2005;115(3):696-703.

15. Quinn GE, Dobson V, Saigal S, Phelps DL, et al. Healthrelated quality of life at age 10 years in very low-birthweight children with and without threshold retinopathy of prematurity. Arch Ophthalmol 2004;122(11):1659-66.

16. Farooqi A, Hägglöf B, Sedin G, Serenius F. Impact at age 11 years of major neonatal morbidities in children born extremely preterm. Pediatrics 2011;127(5):e1247-57.

17. Luu TM, Ment LR, Schneider KC, Katz KH, et al. Lasting effects of preterm birth and neonatal brain hemorrhage at 12 years of age. Pediatrics 2009;123(3):1037-44.

18. Laughon M, O'Shea MT, Allred EN, Bose C, et al. Chronic lung disease and developmental delay at 2 years of age in children born before 28 weeks' gestation. Pediatrics 2009;124(2):637-48.

19. Haywood JL, Morse SB, Goldenberg RL, Bronstein J, et al. Estimation of outcome and restriction of interventions in neonates. Pediatrics 1998;102(2):e20.

20. Morse SB, Haywood JL, Goldenberg RL, Bronstein J, et al. Estimation of neonatal outcome and perinatal therapy use. Pediatrics 2000;105(5):1046-50.

21. Guillén Ú, Suh S, Munson D, Posencheg M, et al. Development and pretesting of a decision-aid to use when counseling parents facing imminent extreme premature delivery. J Pediatr 2012;160(3):382-7.

22. Jobe AH, Bancalari E. Bronchopulmonary dysplasia. Am J Respir Crit Care Med 2001;163(7):1723-9.

23. Papile LA, Burstein J, Burstein R, Koffler H. Incidence and evolution of subependymal and intraventricular hemorrhage: a study of infants with birth weights less than 1,500 gm. J Pediatr 1978;92(4):529-34.

24. Bell MJ. Neonatal necrotizing enterocolitis. N Engl J Med 1978;298(5):281-2.

25. An international classification of retinopathy of prematurity. Pediatrics 1984;74(1):127-33.

26. European Neonatal Network. General report for verylow-birth-weight infants. Data from 2006 to 2011. Bizkaia: EuroNeoNet; 2011. Available at: http:/ /www. euroneonet. eu/paginas/publicas/euroneo/euroneonet/Documents/ ENNGeneralReport2006-2011.pdf. [Accessed on: January 10, 2014].

27. Horbar JD, Carpenter JH, Badger GJ, Kenny MJ, et al. Mortality and neonatal morbidity among infants 501 to 1500 grams from 2000 to 2009. Pediatrics 2012;129(6):1019- 26.

28. Stoll BJ, Hansen NI, Bell EF, Shankaran S, et al. Neonatal outcomes of extremely preterm infants from the NICHD Neonatal Research Network. Pediatrics 2010;126(3):443-56.

29. Shah PS, Sankaran K, Aziz K, Allen AC, et al. Outcomes of preterm infants 29 weeks gestation over 10-year period in Canada: a cause for concern? J Perinatol 2012;32(2):132-8.

30. Guillen Ú, DeMauro S, Ma L, Zupancic L, et al. Survival rates in extremely low birthweight infants depend on the denominator: avoiding potential for bias by specifying denominators. Am J Obstet Gynecol 2011;205(4):329.e1-7.

31. Saigal S, Doyle LW. An overview of mortality and sequelae of preterm birth from infancy to adulthood. Lancet 2008;371(9608):261-9.

32. Bolisetty S, Bajuk B, Abdel-Latif ME, Vincent T, et al. Preterm outcome table (POT): a simple tool to aid counselling parents of very preterm infants. Aust N Z J Obstet Gynaecol 2006;46(3):189-92. 
412 / Arch Argent Pediatr 2014;112(5):405-412 / Original article

33. Perinatal care at the threshold of viability. American Academy of Pediatrics Committee on Fetus and Newborn. American College of Obstetricians and Gynecologists Committee on Obstetric Practice. Pediatrics 1995;96(5 Pt1):974-6.

34. MacDonald H, American Academy of Pediatrics Committee on Fetus and Newborn. Perinatal care at the threshold of viability. Pediatrics 2002;110(5):1024-7.
35. Paul DA, Epps S, Leef KH, Stefano JL. Prenatal consultation with a neonatologist prior to preterm delivery. J Perinatol 2001;21(7):431-7. 


\section{ANNEX 1}

The present study includes the following collaborators to the Neocosur Network:

\section{ARGENTINA}

Guillermo Colantonio, Jorge Zapata, Gastón Pérez, Liliana Rochinotti, Inés Galíndez, Luis Prudent (Clínica y Maternidad Suizo Argentina, Buenos Aires); Gonzalo Mariani, José M. Ceriani Cernadas, Silvia Fernández, Pablo Brener, Carlos Fustiñana (Hospital Italiano, Buenos Aires); Liliana Roldán, Héctor Sexer, Gladys Sáa, Debora Sabatelli, Elizabeth Lombardo, María Laura Gendra, Paula Molina, Jorge Tavosnaska (Hospital Juan Fernández, Buenos Aires); Daniel Agost, Gabriela Torres, Jorge Ríos, Augusto Fischetti, Mónica Rinaldi (Hospital Lagomaggiore, Mendoza); Carlos Grandi, Elio Rojas, Ricardo Nieto, Javier Meritano, Miguel Larguia, Claudio Solana (Maternidad Sardá, Buenos Aires); Marcelo Decaro, Lionel Cracco, Gustavo Bassi, Noemí Jacobi, Edith Martínez, María San Miguel, Andrea Brum, Néstor Vain (Sanatorio de la Trinidad, Buenos Aires).

\section{CHILE}

Jorge Fabres, Alberto Estay, Álvaro González, Mariela Quezada, Soledad Urzúa, Javier Kattan (Hospital Clínico Pontificia Universidad Católica de Chile, Santiago); Solange Rojas, Sandra Vignes, Guillermo Marshall, Luis Villarroel (Unidad Base de Datos, Pontificia Universidad Católica, Santiago); Rodrigo Ramírez, María Eugenia Hübner, Jaime Burgos, Jorge Catalán (Hospital Clínico Universidad de Chile, Santiago); Lilia Campos, Roxana Aguilar, Sergio Treuer, Jimena Giaconi, Aldo Bancalari, Jorge León del Pedregal (Hospital Guillermo Grant, Concepción); Marisol Escobar, Viviana Veas, Daniela Sandino, Antonio Salvado, Alejandra Núñez, Jane Standen (Hospital Gustavo Fricke, Viña del Mar); Agustina González, Claudia Ávila, Ana Luisa Candia (Hospital San José, Santiago); Claudia Toro, Beatriz Milet, Angélica Alegría, Patricia Mena (Hospital Dr. Sótero del Río, Santiago).

\section{PARAGUAY}

Elizabeth Céspedes, Ramón Mir, Elvira Mendieta, Larissa Genes, José Lacarruba (Departamento de Hospital de Clínicas de Asunción).

\section{PERU}

Verónica Webb, Fabiola Rivera, Enrique Bambaren, Marilú Rospigliosi, Margarita Llontop, Jaime Zegarra (Hospital Cayetano Heredia, Lima).

\section{URUGUAY}

Sandra Gugliucci, Ana Lain, Alicia Prieto, Cristina Hernández, Mariza Martínez, Gabriela Bazán, Daniel Borbonet, Rubén Panizza (School of Medicine, Hospital Pereira Rossell, Service of Newborn Infant Care, Montevideo). 